\title{
Impact of Scientific Calculators in Mathematics among Low- Achieving Students in a Secondary School in Kajang, Selangor
}

\author{
Fatimah Salihah Radzuan, Nurzatulshima Kamarudin*, Mas Nida Md Khambari \\ and Nurazidawati Mohamad Arsad
}

Faculty of Educational Studies, Universiti Putra Malaysia, 43400 Serdang, Selangor, Malaysia

\begin{abstract}
This study aims to investigate the effects of scientific calculators on mathematics achievement in support of problem-solving instructions. In this study, 49 low achieving mathematics students aged 14 years were selected from a secondary school in Kajang, Selangor, Malaysia. A pre-test post-test quasi-experimental design with two groups was employed in this action research study. The experimental group learned solid geometry and statistics topics, with the aid of a scientific calculator; while the control group did not use any technological aid to learn these topics. By controlling the pre-test score, the ANCOVA two-way test was applied to the post-test results. A positive significant difference was reported in favour of the experimental group. However, no significant interactions were noted between group and gender. The analysis results indicate that the use of a scientific calculator in the integrated teaching and learning of mathematics helped the students improved their mathematics achievements. These findings have important implications in the educational setting, particularly for educators to support and facilitate low-achieving students in mathematics.
\end{abstract}

Keywords: Achievement, low achieving students, mathematics, problem solving, scientific calculators

\begin{tabular}{|c|c|}
\hline & INTRODUCTION \\
\hline ARTICLE INFO & Since its first introduction in $1970 \mathrm{~s}$ \\
\hline $\begin{array}{l}\text { Article history: } \\
\text { Received: } 13 \text { November } 2020\end{array}$ & classrooms, the calculator has been widely \\
\hline $\begin{array}{l}\text { Accepted: } 11 \text { March } 2021 \\
\text { Published: } 14 \text { April } 2021\end{array}$ & used in mathematics education for decades \\
\hline DOI: https://doi.org/10.47836/pjssh.29.S1.11 & (Kissane, 2020). The pocket calculator \\
\hline $\begin{array}{l}\text { E-mail addresses: } \\
\text { hanzgs33052@gmail.com (Fatimah Salihah Radzuan) } \\
\text { nzshima@@upm.edu.my (Nurzatulshima Kamarudin) } \\
\text { khamasnida@umm.edu.my (Mas Nida Md Khambari) } \\
\text { azidarsad@yahoo.com.my (Nurazidawati Mohamad Arsad) } \\
\text { * Corresponding author }\end{array}$ & $\begin{array}{l}\text { was then commonly accessible due to } \\
\text { its reasonable price, and it influenced } \\
\text { both teachers and students to use it for } \\
\text { teaching and learning (Banks, 2011). Most }\end{array}$ \\
\hline
\end{tabular}


calculators were equipped with limited functionality, functioning as nothing more than effective abacuses for simple arithmetic use. However, this computing tool developed quickly in terms of features and evolved to become more programmed and scientific. Simultaneously, policymakers, scholars, and researchers have been promoting the use of scientific calculators in the teaching and learning of mathematics (Bridget, 2016; Kissane, 2020). While extensive studies have been undertaken to support the use of scientific calculators as a learning tool, significant debate remains concerning the appropriateness of its use in schools.

Many have claimed that the use of calculators in elementary and early middle school classrooms could threaten students' proficiency and fundamental understanding of mathematics. Moreover, students may become too reliant on this learning tool (Line, 2020). Besides, some educators have criticized the fact that students are unable to manually compute basic mathematics and arithmetic skills due to their reliance on the calculator(Klein, 2000). Although educators and the community have expressed concern about this issue, several studies have supported the use of calculators in the classroom. According to National Council of Teachers of Mathematics (2000), calculators are known as pedagogical resources that improve learners' understanding of mathematics.

Moreover, a second-order meta-analysis of 30 years of research conducted by Young (2017) showed that calculators encouraged higher-order thinking by releasing students from excessive computations and encouraging teachers to ask richer questions. Besides, creativity in using computation tools also stimulates students to solve problems (Muhammad Hafizi \& Kamarudin, 2020). In the meantime, Marasigan (2018) suggested that students must practices using these modern devices to navigate their way into the digital age. Practical and meaningful learning methods should be taken into account with proper intention and appropriate planning. As such, students should use the computation tool for computing and understanding mathematical concepts.

Studies in Malaysia have shown that dissatisfaction in mathematics achievement is related to students' difficulties in solving mathematics problems. Students have a hard time understanding and retrieving concepts, formulas, and facts. As they are somehow unable to picture the problems and concepts of mathematics, this causes them to struggle in planning strategies to solve mathematics problems (Parrot \& Leong, 2018). Furthermore, students' frustration and helplessness in answering mathematics questions may have a negative impact on them (Wong \& Wong, 2019). Previous analysis of TIMSS and PISA assessments in mathematical literacy found that most students in Malaysia are unable to interpret information to solve complicated mathematics problems (Tajudin \& Chinnappan, 2016). Other studies often indicated that students who have trouble 
dealing with the mathematical task tend to memorize steps or formulas of the mathematical solution and thus fail to grasp the mathematical principles, processes, and relationships (e.g., Embong et al., 2020).

This condition leads to poor mathematical performance and has a massive influence, especially on lowachieving students. However, several studies have suggested these issues can be overcome by supporting students to use technology in their learning environment. Wong and Wong (2019) stated that lowachieving students showed a strong interest in mathematics. Mathematics performance is enhanced when technological tools and resources like a calculator support their learning environment. A quasi-experiment study by Kandemir and Demirbağ-Keskin (2019) found that using the calculator to solve mathematical problems indicated significant positive differences favouring the experimental group. Kissane (2020) suggested that providing a calculator aided in student learning and nurtured them to be thoughtful users. Additionally, many believe that technology can help students learn concepts by checking their work and guiding them in the right direction to solve mathematical problems (Costley, 2015). Furthermore, Young (2017) reported that a prior meta-analysis of the impact of calculators on mathematics achievement was influential. Thus the use of calculators should be embraced as pedagogically relevant resources.
Gender is another factor influencing students' achievement. The PISA assessment analysis by Thien and Ong (2015) discovered that Malaysian female students performed better than male students in mathematics literacy. This statement is supported by Taylor and Dalal (2017) whose results survey stated females were more likely to have 49 percent marks compared to males with 37 percent in mathematic literacy based on their mean results. Besides, Thien and Ong (2015) reported that girls significantly outperformed boys in three categories of mathematical content (i.e., foundation, basic facts, and application) and processes. More recent trend analysis by Tajudin and Chinnappan (2016) as well as Ahmad et al. (2017) revealed that in most countries in Asia, girls had a better academic performance than boys.

Further, the results from the Malaysian standard public examination also indicated that girls performed better than boys. According to Tajudin and Chinnappan (2016), this problem is specific to Malaysia and other countries. Concerning this issue, the country needs to be vigilant in ensuring that it does not have a cohort of 'lost boys' leaving school early or with lowperformance levels. Hence, to overcome this problem, an effective intervention has been proposed involving a technology resource, such as a calculator. Therefore, this study aimed to explore the effects of using scientific calculators on mathematics learning, focusing on Form Two secondary school students with low achievement in mathematics. 


\section{LITERATURE REVIEW}

Mathematics education begins with conventional mathematics that emphasizes mainly basic skills and is predominantly computational. However, the Malaysian mathematics curriculum has undergone several significant changes over the last five decades. In the early seventies, all primary and secondary schools were introduced to the "Modern Mathematics Program" (MMP). The program's main goal was to incorporate a range of new "modern topics," including simplified basics in set theory, statistics, and vectors. To shift the "traditional" approach commonly used in mathematics teaching and learning, integrating technology resources was infused into this learning (Price, 2015). Thus, in 2003, the Ministry of Education (MOE) permitted the use of scientific calculators for Form Two students in secondary schools (The Star, 2003). Scientific calculators have become a standard technological tool in the Malaysian education system for all students at various levels, and most students use them during mathematics lessons. The use of the scientific calculator is also allowed in the Sijil Pelajaran Malaysia (SPM) examination.

Although the scientific calculator has been used extensively until today in teaching and learning mathematics, an analysis from the Trend in International Mathematics and Science Study (TIMSS) found that research on the use of scientific calculators among Malaysian students was only conducted until 2007 (Rebecca, 2013). There is a lack of recent studies on the use of scientific calculators among students in Malaysia.
Furthermore, it is challenging to obtain any information or data on using scientific calculators since researchers have barely conducted studies in this area (Parrot \& Leong, 2018). For example, using a grey resources database (i.e., Google Scholar) between the years 2016 to 2020 , the researchers manage to only obtain 38 articles or books with the keywords "scientific calculator" and "mathematics". A scientific calculator is not only a tool to perform mathematical computations, but it can also be used as a tool for understanding mathematical concepts. Despite the myths of harmful consequences resulting from its use, a scientific calculator gives an excellent value as a pedagogical tool that benefits educators and students (Kharuddin \& Ismail, 2017).

Several studies have shown that utilizing scientific calculators as an instructional tool helps enhance critical thinking, understanding of connections among graphical, tabular, numerical, and algebraic representations, and allows students to improve their confidence in mathematics (Ochanda \& Indoshi, 2011). Scientific calculators make mathematical calculations easier and more precise. This technological tool enables students to expand their mental abilities when its use is integrated into the teaching and learning of mathematics (Darling-Hammond et al., 2020). For example, a scientific calculator provides a quick, easy, and accurate alternative. Utilizing a scientific calculator helps students to obtain the correct answers faster than even the most seasoned mental arithmeticians. 
Once students have mastered the use of the scientific calculator, they do not have to spend the same amount of time applying mathematical concepts (Darling-Hammond et al., 2020). Research by Agustyaningrum, et al. (2018) found that low-achieving students minimized their carelessness and computational errors when using a scientific calculator to solve mathematics problems. These students had difficulties understanding mathematical concepts and ideas that underlied mathematical problems (Sivasubramaniam \& Kamarudin, 2020). However, when they can speed up the learning process by spending less time on tedious calculations (Darling-Hammond et al., 2020), they can invest more time into understanding and solving problems. A scientific calculator enables students to build a better sense of numbers and consolidate their mathematical concepts (Marasigan, 2018).

Low-achieving students tend to spend more time understanding intangible concepts through tangible means to solve mathematical problems using scientific calculators. This technology tool allows students to deal with much more complicated and profound issues than ever before, which most students could not solve previously (Banks, 2011). It seems that while conventional mathematical methods of problem-solving tend to disable a significant number of students, scientific calculators act as an equalizer. Students can now delve deeper into the subject, develop their reasoning skills, handle numbers, and obtain mathematical insight into the process using scientific calculators in learning mathematics.
In addition to developing students' cognitive skills, using the scientific calculator to solve mathematical problems helps students gain confidence in their mathematics abilities. Students become confident enough to manage any mathematical situation without being hindered by fear and anxiety about mathematics (Bridget, 2016). To enhance low-achieving students' achievement in mathematics, they must eliminate their fear and anxiety about mathematics. Therefore, an appropriate teaching approach with the integration of scientific calculators in mathematics lessons enables low-achieving students to become more optimistic and eventually improve their mathematics achievements.

Educational statistics and worldwide media have reported a clear gender gap in academic achievement between males and females, with the first lagging behind the latter in terms of subject grades, secondary school graduation, tertiary level enrolment and completion of school (Parker et al., 2018). The superior performance of females over males in secondary school and other education levels appears to be a growing international phenomenon. A recent and significant comprehensive global meta-analysis that examined malefemale performance at all levels revealed that girls had always outperformed boys in school (Marc Jackman et al., 2019). This data means gender can be a factor that influences students' achievements even though technological aids are used in integrated teaching and learning during mathematics lessons. 
The integrative teaching and learning theory is rooted in many other teaching and learning theories, including situated cognition, constructivism, and projectbased learning (Ceker \& Ozdamli, 2016). Integrative teaching and learning approaches distils these ideas into several main facts. First, to teach and learn, education must be student-centred and student-driven. Assignments must be relevant to teachers and students as well as the world around them. Finally, education should emphasize exploration, real-life experiences, and hands-on projects.

Integrated teaching and learning approaches can be described as actions that enable students to explore, collect, process, refine, and present information on topics they wish to investigate without the requirements imposed by traditional subject barriers (Pigdon \& Woolley, 1992). An integrated approach allows students to engage in purposeful and relevant learning, for example, by using a scientific calculator in learning mathematics. Integrated teaching and learning can be defined as teaching and learning integrated lessons that enable students to create connections across the curricula (Costley, 2015). In this study, an integrated teaching and learning approach implemented is outside the typical or traditional teaching method, and learning mathematics using a scientific calculator is explored among low-achieving mathematics students.

Successful integrated teaching and learning may have a positive impact on low-achieving mathematics students' performance. Therefore, a practical and exciting integrated teaching and learning process can result in a more active learning process among students (Ghavifekr \& Rosdy, 2015). Using scientific calculators can encourage low-achieving students to be more interested in learning mathematics as they acquire new skills from using the scientific calculator to solve mathematical problems. With effective integrated teaching and learning using a scientific calculator, low-achieving mathematics students are more likely to improve their performance. Integrated teaching and learning can foster a conducive learning environment for students. Nevid and Gordon (2018) argued that it would be useful for students to use the integrated teaching and learning approach during mathematical lessons in the classroom. Students are more focused and actively involved in the learning process, thus contributing to better results in their mathematical understanding.

\section{MATERIALS AND METHODS}

\section{Research Design}

In this study, the action research design with an embedded quasi-experimental study was adopted (Ramlal \& Augustin, 2020). Action research is a method of investigation designed for teachers to solve problems in their classrooms and improve professional practices (Parsons \& Brown, 2002). This method includes systematic observations and data collection, which the practitioner-researcher uses to represent, evaluate, and establish a more efficient classroom strategy to improve mathematics 
performance among students, regardless of gender. Action research was selected for the current study because the researcher aimed to promote the use of scientific calculators to solve mathematics problems. Practical action research focuses on teachers' growth and students' learning. Implementing practical action research in the classroom enables a teacher to become a researcher.

Practical action research includes four key points (Mills, 2000): (i) focus area, (ii) action plan, (iii) data collection and analysis, and (iv) data interpretation. This study focuses on helping low-achieving students improve their mathematical achievements, particularly for solid geometry and statistical topics. Therefore, this study created instructions on how students should use scientific calculators to solve math problems in solid geometry and statistics. The research questions, method, and assessment were also included in this study before the new idea of instruction was introduced in the classroom.

The data were collected from a quasiexperimental study (equivalent to the experimental and control groups) with a pretest-posttest design. In this research, the students in the control group conventionally solved mathematics problems without using any technological device. Meanwhile, in the treatment group, students used a scientific calculator as a learning aid. The pre-test and post-test data were then analysed using a sufficient analysis. Finally, the analysed data were interpreted to determine the effectiveness of the intervention. Practically, the use of the action research design was to help teachers and students collaborate in improving their teaching and learning strategy, which would support the low-achieving students to improve their mathematical performance.

\section{Participants}

The participants in this study were Form Two students of a low level of achievement at a secondary school in Kajang, Selangor, Malaysia. The students were selected according to their previous mathematics examination results of less than 50 marks. A total of 100 students with poor achievement in mathematics were identified, and all of them studied in the intensive classes with the same teacher. However, only 74 students were willing to voluntarily participate in this study. To test the validity and reliability of the instruments, a pilot test was conducted involving 25 selected students to whom the instruments were administered.

The action research was implemented among the rest of the students (see Table 1). The students were selected randomly and assigned into two groups (treatment group and control group). In the treatment group, the explanation and instructions for using a scientific calculator were provided in the learning and teaching process. There were 25 students consisting of 11 boys (44\%) and 14 girls (56\%). Meanwhile, for the control group, the conventional approach (chalk and talk) and mathematics drilling exercises were performed without using a scientific calculator or other devices. There were 24 students made up of 12 boys (50\%) and 12 girls $(50 \%)$. 
Table 1

Distribution of samples for each group according to gender $(N=49)$

\begin{tabular}{lcccc}
\hline \multirow{2}{*}{ Gender } & \multicolumn{2}{c}{ Control group } & \multicolumn{2}{c}{ Treatment group } \\
\cline { 2 - 5 } & Frequency & Percentage & Frequency & Percentage \\
\hline Boys & 12 & 50.0 & 11 & 44.0 \\
Girls & 12 & 50.0 & 14 & 56.0 \\
Total & 24 & 100.0 & 25 & 100.0 \\
\hline
\end{tabular}

\section{Instruments}

The mathematics achievement test (MAT) instrument had the format of subjective questions. This instrument was used for both the pre-test and post-test. The Form Three Assessment (PT3) questions related to the Solid Geometry and Statistics topics were collected from the PT3 examination question banks to construct the MAT. Two experts in mathematics with over 15 years of experience were invited to conduct the face and content validation of the test. Finally, a total of 10 items were used in the instrument. The items were then administered for pilot testing to 25 Form Two low-achieving mathematics students. By measuring the internal consistency, the instrument's reliability was analysed using the KuderRichardson formula (KR21). The internal coefficient was 0.732 . This coefficient value is considered good; therefore, the MAT was regarded as an acceptable instrument for this research.

\section{Data collection and analysis}

In experimental research, both the experimental group and control groups were given the MAT pre-tests and posttests. The participants took the pre-test before the intervention began, while the post-test was conducted immediately after the intervention in six learning sessions after each session ended. The MAT score was analysed using IBM SPSS statistic version 25 . The participants' demographics were represented using descriptive statistics such as mean, standard deviation (SD), frequency, and percentage. The scale score was compared using the mean and SD. To determine the differences in the mean of post-test scores for the control and intervention groups, an analysis of covariance (ANCOVA) was conducted. ANCOVA determines whether the post-test mean scores with the pre-test scores as a covariate differ between two groups. Before performing the ANCOVA, the assumptions of this analysis were tested, which include normality, variance homogeneity, and regression slopes homogeneity.

\section{RESULTS}

The mean score of the mathematics achievement test (MAT) was computed and compared with group (control and treatment) and gender. The data presented in Table 2 indicates that there is a big difference in the overall post-test mathematics means scores between groups, where the mean of the treatment group $(\mathrm{M}=29.400 ; S D=8.129)$ 
Table 2

Descriptive statistic

\begin{tabular}{lllllll}
\hline \multirow{2}{*}{ Group } & Gender & \multicolumn{2}{c}{ Pre-test $(\boldsymbol{n}=\mathbf{2 4})$} & \multicolumn{2}{c}{ Post-test $(\boldsymbol{n}=\mathbf{2 5})$} & \multirow{n}{*}{$\boldsymbol{n}$} \\
\cline { 3 - 5 } Control group & Mean & SD & Mean & SD & & 12 \\
& Boys & 3.250 & 2.221 & 12.667 & 5.742 & 12 \\
& Girls & 4.000 & 1.954 & 11.083 & 4.481 & 24 \\
\multirow{2}{*}{ Treatment group } & Total & 3.625 & 2.081 & 11.875 & 5.102 & 11 \\
& Boys & 4.546 & 2.067 & 28.636 & 9.277 & 14 \\
\multirow{2}{*}{ Total } & Girls & 3.000 & 1.569 & 30.000 & 7.411 & 25 \\
& Total & 3.680 & 1.930 & 29.400 & 8.129 & 23 \\
\hline
\end{tabular}

Abbreviation: SD, standard deviation.

is higher than that of the control group (M $=11.875 ; S D=5.102)$. Meanwhile, there is a slight difference in the overall pre-test mathematics means scores between the control group $(\mathrm{M}=3.625 ; S D=2.081)$ and treatment group $(\mathrm{M}=3.680 ; S D=$ 1.930). The comparison of the post-test mathematics means scores between gender shows that girls $(\mathrm{M}=30.000 ; S D=7.411)$ outperformed boys $(\mathrm{M}=28.636$; $\mathrm{SD}=$ 9.277 ) in the treatment group. However, in the control group, boys $(\mathrm{M}=12.667 ; S D$ $=5.742)$ outperformed girls $(\mathrm{M}=11.083$; $S D=4.481)$. Despite these findings, there is only a slight difference in the mean score between genders for both groups.

To test this hypothesis, a two-way between-groups analysis of covariance was used. The test involved a 2-by-2 between-groups analysis of covariance. The independent variables were the type of instructional approach (conventional and using the scientific calculator) and gender (boys and girls) with a low achievement in mathematics. The dependent variable was the scores on mathematics achievement test (MAT) administered following the completion of the treatment (posttest). The MAT scores obtained prior to the commencement of treatment (pretest) were used as covariates to control for individual differences.

Prior to comparing the changes in the pre-post test scores for the intervention and control groups, the ANCOVA assumptions were conducted, including normality, homogeneity of variances, and homogeneity of regression slopes. The normality of the data can be assessed through the value of kurtosis and skewness. The analysis indicated that the data were normally distributed as the skewness $(-0.559 \sim 0.082)$ and kurtosis $(-1.0 \sim 0.270)$ were within \pm 1 (Mishra et al., 2019). Meanwhile, the Levene's test for homogeneity of variances is significant ( $p>0.05, p=0.004)$, thus confirming that the variances of the group are not equal. However, this test is not the only way to measure variance. As an alternative, Henseler et al. (2015) suggested 
investigating the variance ratio. Using Hartley's $F_{\max }$ test to estimate the variance ratio, the results show that $\mathrm{F}=4.285$ is smaller than Harley's $F_{\max }$ table $=4.503(\mathrm{df}$ $=13, \mathrm{k}=4$ ), indicating that the variances are equal and homogenous. Next, the homogeneity of regression slopes analysis was conducted to ensure that there was no interaction between the variables.

As shown in Table 3, all interactions between the independent variables (group and gender) and the pre-test scores are $>$ 0.05 , demonstrating that the homogeneity of regression is not violated. Since all the assumptions were complied, it was therefore appropriate to conduct the ANCOVA analysis.

The ANCOVA two-way test observes that the group's effect was statistically significant, $F(1,48)=76.607, p<0.05$. There was no significant interaction effect between the groups and gender as the significance value shown in Table 4 is 0.308 , which is above the 0.05 cut-off value. The results suggest that the type of interventions in the group contributed to improving mathematics achievement. Further analysis regarding the group effect was performed to identify the significant impact of different interventions on mathematics achievement (See Table 5).

Table 3

Homogeneity of regression slopes for group - gender - covariate interactions.

\begin{tabular}{lcc}
\hline \multicolumn{1}{c}{ Interaction } & $\boldsymbol{F}$ & $\boldsymbol{p}$ \\
\hline group * pretest & 0.178 & 0.676 \\
gender * pretest & 0.085 & 0.772 \\
group * gender * pretest & 0.784 & 0.381 \\
\hline
\end{tabular}

Significant value at $\mathrm{p}<0.05$

Table 4

Tests of between-subjects effects on mathematics achievement

\begin{tabular}{lccccccc}
\hline \multicolumn{1}{c}{ Source } & $\begin{array}{c}\text { Sum of } \\
\text { Squares }\end{array}$ & df & $\begin{array}{c}\text { Mean } \\
\text { Square }\end{array}$ & $\boldsymbol{F}$ & $\boldsymbol{p}$ & $\begin{array}{c}\text { Partial eta } \\
\text { squared }\end{array}$ & $\begin{array}{c}\text { Observed } \\
\text { power }\end{array}$ \\
\hline group & 3657.284 & 1 & 3657.284 & 76.607 & $\mathbf{0 . 0 0 0}$ & 0.635 & 1.000 \\
gender & 0.176 & 1 & 0.176 & 0.004 & 0.952 & 0.000 & 0.050 \\
group * gender & 50.875 & 1 & 50.875 & 1.066 & 0.308 & 0.024 & 0.173 \\
\hline
\end{tabular}

Significant value at $\mathrm{p}<0.05$

Table 5

Estimated marginal means scores for mathematics achievement between groups

\begin{tabular}{lcccc}
\hline \multirow{2}{*}{ Group } & M & Std. error & \multicolumn{2}{c}{$\mathbf{9 5 \%}$ Confidence Interval } \\
\cline { 4 - 5 } & & & Lower Bound & Upper Bound \\
\hline Control & 11.891 & 1.410 & 9.049 & 14.734 \\
Treatment & 29.249 & 1.393 & 26.441 & 32.057 \\
\hline
\end{tabular}


Table 5 indicates a huge difference in the mean scores between the control group ( $\mathrm{M}=$ 11.891) and treatment group $(M=29.249)$. Based on the above findings, the students using the scientific calculator performed better than the conventional group students in solving mathematics problems.

\section{DISCUSSION}

This research explored the impact of scientific calculators on mathematics achievement among secondary school students in Kajang, Selangor, Malaysia. The low-achieving students in mathematics designated as the treatment group (using a scientific calculator) demonstrated a higher mathematics performance than those in the conventional group. These results suggest that using scientific calculators as a technological tool in learning mathematics can improve students' achievements, particularly among low-achieving students. In addition, the large effect sizes of the groups support the significant impact of the intervention on mathematics achievement.

Consistent with previous studies (Bridget, 2016; Kissane, 2020; Parrot \& Leong, 2018), integrating technology in learning mathematics improves students' mathematics achievements. This study suggested that encouraging students to learn mathematics using calculators, particularly in Solid Geometry and Statistics topics, may help low-achieving students to enhance their understanding. Using a scientific calculator also has a positive impact on students' ability to solve problems. This finding is supported by other researchers who postulated that students are better problem solvers when computation tools are used in class (Parrot \& Leong, 2018). Research shows that the integrated teaching and learning approach enables students to solve mathematics problems efficiently.

Davies and West (2014) stated that integrating technological tools in an integrative teaching and learning approach provided students with a better learning process. Consequently, students can expand their scope of cognitive abilities (DarlingHammond et al., 2020). In this learning approach, student-centred and studentdriven principles are emphasized. Students are encouraged to take responsibility for their learning in solving problems and inquiry. With the assistance of a scientific calculator, mathematics problems are posed to students and the solving process is done without the teacher's guidance. Also, students are asked to create their own, personally meaningful solutions. In both cases, the students act as the problem solvers and they use critical thinking skills and reasoning to develop their solutions (Stephan, 2014). Furthermore, this learning approach encourages students to perform tasks relevant to their surroundings as well as use real-world materials and experiences. Besides, students become more confident in managing various mathematical situations without being hindered by fear and anxiety when solving complicated mathematics problems.

Generally, all low-achieving students in this study were given a similar input on both topics. Thus, there are no biases in their 
basic concept knowledge on solid geometry and statistic. This way, the researcher could determine whether a scientific calculator used in the integrative teaching approach has a sole impact on the students' mathematics performance. However, the results indicated that the students' mathematics achievements in the conventional teaching approach without using scientific calculators also improved. According to Darling-Hammond et al. (2020), a learning process takes place amongst students based on their performance and achievements. That said, the difference is not significant. The students in the control group did not do as well as the students using scientific calculators because the former needed more time to do basic computations and had less time to understand the mathematical concept. According to Agustyaningrum et al. (2018), low-achieving students tend to commit careless computation mistakes when they do manual calculations because it is difficult to do in a limited time.

More interestingly, the study found that the gender-related analyses on mathematics achievement do not indicate any significant difference between genders. This result contradicts the findings reported by Thien and Ong (2015), Ahmad et al. (2017), and Tajudin and Chinnappan (2016), as these researchers found significant differences among girls and boys, where girls performed better than boys. However, the descriptive mean score of low-achieving students who used scientific calculators shows a similar result with the PISA data analysis explored by Gevrek et al. (2020), where there was a difference in mathematics scores in favour of girls. This result was only found in several countries in Asia, including Malaysia and Kazakhstan. However, there were no consistent findings that could explain this difference. Hence, future studies are suggested to further investigate gender and achievement to evaluate this pattern. Not only that, other previous studies have indicated that gender alone is unable to explain this phenomenon. Thus, there is a need to include other vital variables in future studies, such as socio-economic status.

To summarize the empirical findings and discussion, scientific calculators can be considered beneficial in improving learning experiences among low-achieving students. The results of the current study provide promising evidence for addressing a significant issue regarding mathematics achievement. It has been acknowledged that low-achieving students tend to have lower performance and engagement in mathematics. However, utilizing technological resources that can be easily accessed by all students, such as scientific calculators, will lead to a smaller gap in mathematics achievement between highachieving and low-achieving students. Additionally, this study's findings suggest a promising future for low-achieving students in that they can also be successful like their high-achieving counterparts regardless of their current level of achievements in mathematics.

Although this study presents evidence on the impact of scientific calculators on students' mathematics achievement, it 
also has some limitations. First, the study was conducted only within a specific context with specific characteristics of students and selected mathematics topics. Hence, this poses limitations on the study's generalizability. Second, the study's methods and instruments are only limited to quantitative methods using mathematics achievement test scores to measure students' performance. Therefore, additional research using more in-depth qualitative methods, such as in-depth interviews and observation, should be conducted in order to capture and obtain information, particularly on students' conceptual context in solving mathematics problems.

\section{CONCLUSION}

This study provides empirical evidence that using a scientific calculator can increase low-achieving students' achievement in mathematics. These findings suggest that effective instruction including the use of a scientific calculator to solve a mathematical problem can encourage low-achieving students to improve their mathematics achievement. A scientific calculator is advantageous for low-achieving students; it enables them to complete mathematics tasks with minimal computational errors and provides them with more time to understand mathematical concepts. The impact of the COVID-19 pandemic forces schools and institutes worldwide to apply digital learning in order to ensure students can continue learning at home. To have continuity in using the computational tool, it is recommended that teachers encourage students to utilize an online scientific calculator to support and assist low-achieving students in learning mathematics. A web-based calculator for calculation, graphing, geometry, and statistics that can be accessed in ClassPad. net provided by Casio is a fantastic resource for students to learn mathematics.

\section{ACKNOWLEDGEMENT}

The authors would like to thank all the students who participated in this study. Special thanks of gratitude also go to the Publication and Citation Unit (PACU), Faculty of Educational Studies, UPM for giving the golden opportunity and extraordinary support to complete this article for publication.

\section{REFERENCES}

Agustyaningrum, N., Abadi, A. M., Sari, R. N., \& Mahmudi, A. (2018). An analysis of students' error in solving abstract Algebra tasks. Journal of Physics: Conference Series, 1097(1), 1-13. doi: 10.1088/1742-6596/1097/1/012118

Ahmad, N., Hassan, S. A., Ahmad, A. R., Lay Nee, C., \& Othman, N. H. (2017). The trend of academic achievement among Malaysian boys and girls: Where are the boys? Global Journal of Business \& Social Science Review, 5(1), 1-8.

Banks, S. (2011). A historical analysis of attitudes toward the use of calculators in junior high and high school math classrooms in the United States since 1975 [Master thesis]. Cedarville University.

Bridget, M. S. (2016). The influence of using a scientific calculator in learning fractions: A case study of one school in Gauteng Province [Master thesis]. University of South Africa https://www. semanticscholar.org/paper/The-influence-of- 
using-a-scientific-calculator-in-\%3A-Mutsvan gwa/1a05f458a4ee6ce01ba57b05fa884802b41 fc189?p2df

Ceker, E., \& Ozdamli, F. (2016). Features and characteristics of problem based learning. Cypriot Journal of Educational Sciences, 11(4), 195-202.

Costley, K. C. (2015). Research supporting integrated curriculum: Evidence for using this method of instruction in public school classrooms $[\mathrm{PhD}$ thesis]. Arkansas Tech University.

Darling-Hammond, L., Flook, L., CookHarvey, C., Barron, B., \& Osher, D. (2020). Implications for educational practice of the science of learning and development. Applied Developmental Science, 24(2), 97-140. doi: 10.1080/10888691.2018.1537791

Davies, R. S., \& West, R. E. (2014). Technology integration in schools. In M. Spector, M. Merrill, J. Elen, \& M. J. Bishop (Eds.), Handbook of research on educational communications and technology (4th Ed., pp. 841-853). Springer.

Embong, Z., Khalid, M., Adnan, N. S. M., \& Razikin, M. (2020). Exploration of the low arithmetic achievement on primary students: Teacher's perspectives. Journal of Physics: Conference Series, 1529(3), 1-8. doi: 10.1088/1742$6596 / 1529 / 3 / 032018$

Gevrek, Z. E., Gevrek, D., \& Neumeier, C. (2020). Explaining the gender gaps in mathematics achievement and attitudes: The role of societal gender equality. Economics of Education Review, 76, 1-31. doi: 10.1016/j.econedurev.2020.101978

Ghavifekr, S., \& Rosdy, W. A. W. (2015). Teaching and learning with technology: Effectiveness of ICT integration in schools. International Journal of Research in Education and Science (IJRES), 1(2), 175-191.
Henseler, J., Ringle, C. M., \& Sarstedt, M. (2015). A new criterion for assessing discriminant validity in variance-based structural equation modeling. Journal of the Academy of Marketing Science, 43(1), 115-135.

Kandemir, M. A., \& Demirbag Keskin, P. (2019). Effect of graphing calculator program supported problem solving instruction on mathematical achievement and attitude. International Journal of Research in Education and Science (IJRES), 5(1), 203-223.

Kharuddin, A. F., \& Ismail, N. A. (2017). Graphing calculator exposure of mathematics learning in a partially technology incorporated environment. EURASIA Journal of Mathematics, Science and Technology Education, 13(6), 2529-2537. doi: 10.12973/eurasia.2017.01238a

Kissane, B. (2020). Integrating technology into learning mathematics: The special place of the scientific calculator. Journal of Physics: Conference Series, 1581(1), 1-15. doi: 10.1088/1742-6596/1581/1/012070

Klein, D. (2000). Math problems: Why the department of education's recommended math programs don't add up. American School Board Journal, 187(4), 52-57.

Line, B. (2020). The effects of restrictions on calculator usage in high school Algebra 1 Classes [PhD thesis]. Ohio Dominican University.

Marasigan, N. V. (2018). Examining calculator use in the mathematics classroom. International Journal of Recent Innovations in Academic Research, 2(8), 165-170.

Marc Jackman, W., Morrain-Webb, J., \& Fuller, C. (2019). Exploring gender differences in achievement through student voice: Critical insights and analyses. Cogent Education, 6(1), 1-19. doi: 10.1080/2331186X.2019.1567895 
Mills, G. E. (2000). Action research: A guide for the teacher researcher. Prentice-Hall, Inc.

Mishra, P., Pandey, C. M., Singh, U., Gupta, A., Sahu, C., \& Keshri, A. (2019). Descriptive statistics and normality tests for statistical data. Annals of Cardiac Anaesthesia, 22(1), 67-72.

Muhammad Hafizi, M. H., \& Kamarudin, N. (2020). Creativity in mathematics: Malaysian perspective. Universal Journal of Educational Research, 8(3), 77-84.

National Council of Teachers of Mathematics. (2000). Principles and standards for school mathematics. NCTM.

Nevid, J. S., \& Gordon, A. J. (2018). Integrated learning systems: Is there a learning benefit? Teaching of Psychology, 45(4), 340-345. doi: $10.1177 / 0098628318796920$

Ochanda, J. P., \& Indoshi, F. C. (2011). Challenges and benefits of using scientific calculators in the teaching and learning of Mathematics in secondary school education. Journal of Media and Communication Studies, 3(3), 102-111. doi: 10.5897/JMCS.9000014

Parker, P. D., Van Zanden, B., \& Parker, R. B. (2018). Girls get smart, boys get smug: Historical changes in gender differences in math, literacy, and academic social comparison and achievement. Learning \& Instruction, 54, 125-137. doi: 10.1016/j.learninstruc.2017.09.002

Parrot, M. A. S., \& Leong, K. E. (2018). Impact of using graphing calculator in problem solving. International Electronic Journal of Mathematics Education, 13(3), 139-148. doi: 10.12973/ iejme/2704

Parsons, R., \& Brown, K. (2002). Teacher as reflective practitioner and action researcher. Wadsworth.

Pigdon, K., \& Woolley, M. (1992). The BIG picture. Eleanor Curtain Publishing.
Price, J. K. (2015). Transforming learning for the smart learning environment: Lessons learned from the Intel education initiatives. Smart Learning Environments, 2(1), 1-16. doi: 10.1186/s40561015-0022-y

Ramlal, A., \& Augustin, D. S. (2020). Engaging students in reflective writing: An action research project. Educational Action Research, 28(3), 518-533. doi: 10.1080/09650792.2019.1595079

Rebecca, G. (2013). Research summary - A brief review of calculator usage in mathematics. Cambridge: Assessment research and development. Cambridge Assessment.

Sivasubramaniam, P. A. P., \& Kamarudin, N. (2020). Using ordering tasks to determine fraction magnitudes. Universal Journal of Educational Research, 8(1), 147-155.

Stephan, M. (2014). Learner-centered teaching in mathematics education. In L. Stephan (Ed.), Encyclopedia of mathematics education (pp. 338-343). Springer.

Tajudin, N. A. M., \& Chinnappan, M. (2016). The link between higher order thinking skills, representation and concepts in enhancing TIMSS tasks. International Journal of Instruction, 9(2), 199-214. doi: 10.12973/iji.2016.9214a

Taylor, A., \& Dalal, H. A. (2017). Gender and information literacy: Evaluation of gender differences in a student survey of information sources. College and Research Libraries, 78(1), 90-113. doi: 10.5860/crl.78.1.90

The Star. (2003, March 14). Scientific calculators allowed. The Star. https://www.thestar.com. my/news/education/2003/03/16/scientificcalculators-allowed

Thien, L. M., \& Ong, M. Y. (2015). Malaysian and Singaporean students' affective characteristics and mathematics performance: Evidence from PISA 2012. SpringerPlus, 4(1). doi: 10.1186/ s40064-015-1358-Z 
Wong, S. L., \& Wong, S. L. (2019). Relationship between interest and mathematics performance in a technology-enhanced learning context in Malaysia. Research and Practice in Technology Enhanced Learning, 14(1), 21-34. doi: 10.1186/ s41039-019-0114-3
Young, J. (2017). Technology-enhanced mathematics instruction: A second-order meta-analysis of 30 years of research. Educational Research Review, 22, 19-33. doi: 10.1016/j.edurev.2017.07.001 